\title{
Extending influence and accounting use-Developing the Frameworks to incorporate Galician legal matters about the proposed healthcare changes with managers and organizations for empirical study
}

\author{
Derek E. Purdy ${ }^{\mathrm{a}, *}$, Susana Gago ${ }^{\mathrm{b}}$ \\ ${ }^{a}$ Department of Management, University of Reading, PO Box 218, Reading RG6 6AA, United Kingdom \\ b Department of Economía de la Empresa, Carlos III University of Madrid, \\ University of Santiago de Compostela, Calle Madrid, 126, 28903 Getafe, Madrid, Spain
}

Received 1 August 2005; received in revised form 20 March 2006; accepted 1 April 2006

\begin{abstract}
The previous paper provided the general approach to Frameworks of research and research methods to study accounting changes in Galician healthcare [Purdy DE, Gago S. Towards a framework to study influence and accounting use. Critical Perspectives on Accounting, 2003;14:663-78]. Consideration of the Galician legal and institutional materials provided the details and indicated the need for further analysis. This paper analyses Galician materials and the Spanish notion of retos, considers autonomy in the context of influence and changing information provision. Consequently, the Information-Influence Matrix is revised as are those anticipated for a Financial Manager and a Health Centre Manager. Further Frameworks now consider the organization and institution effects.

Work elsewhere has indicated that the promotion of more involvement by employees and the provision of more information to employees has been accompanied by strong narratives favouring
\end{abstract}

\footnotetext{
* Corresponding author.

E-mail addresses: D.E.Purdy@ reading.ac.uk (D.E. Purdy), sgago@emp.uc3m.es (S. Gago).
} 
such changes. Generally such change has been more favourable for managers than non-management employees.

Keywords: Information; Influence; Autonomy; Managers; Galician Health Centre Management; Personal Construct Psychology; Information-Influence Matrix; Organizational Change; Accounting data

\section{Background}

The interaction of individuals and financial management data is a subject of current interest to accounting and organization research. The authors learned of impending changes in Galician Health Centres and considered that this occasion was an opportunity to add to our knowledge about people and accounting data. A previous paper set out, in general terms, the authors' Frameworks of research, or theoretical perspectives, and some of their research methods. The conclusion noted that the Frameworks could be used to evaluate fieldwork (Purdy and Gago, 2003).

After completing the previous paper we studied the details of the Galician legal and institutional materials about the proposed healthcare management changes. Some further matters emerged. Although the Initial Framework was soundly specified in general terms, these further matters indicated a need to enhance the Initial Framework and amend it to be as specific about the legal position with our anticipations, as we could before we analysed our empirical observations. This has resulted in this paper which deals with the anticipated Legal Institutional Context to a Framework of Issues for both the Health Centre Manager and the Upper Manager.

We also noted that the proposed changes in Galician healthcare would affect the organizational/institutional arrangements, consequently, the theoretical approaches of the Frameworks that assist with the interpretation of individuals, have been re-interpreted/re-assigned for use as Frameworks for the interpretation of organizational arrangements.

This paper discusses the development of these Frameworks and a more specifically related set of ideas with which to handle our analysis of the Galician interviews. The introduction very briefly summarises the previous literature with the empirical and theoretical development of the area, then the earlier paper's Information-Influence Matrix and the specification of the Initial Framework (Purdy and Gago, 2003).

Section 3, the Galician Context, contains explanations about the legal matters and is followed by a section with our observations on these. The relevant parts of these legal matters were translated and discussed in English. In particular we re-consider our ideas about influence, with the introduction of autonomy and then the changing nature of information mentioned in the legislation. In the fifth section, we critically evaluate the underlying norms which we had adopted towards the legislation and introduce some literature of similar changes elsewhere.

The sixth section sets out the Implications for the Framework and developing our Framework, individually, for both managers. There are revisions to the initial Information-Information Matrix, Personal Matrix and also the Frameworks of Issues for the Personal Information Influence Matrix changes anticipated for a Financial Manager and 
then a Health Centre Manager. The seventh section produces an Organization Information Influence Matrix for Health Centres and from this a Framework of Organization Issues for the Health Centres. A brief summary and conclusions completes the paper. Consistent with our writing practice, we use the male form in this paper, simply because males were in the majority in helping with this paper and our subsequent empirical work.

\section{Introduction}

\subsection{Previous literature}

There has been a long held interest in the provision of accounting data to an organization's employees and appreciations of the different contexts that have fostered its provision and use by employees. These social constructions of organizational activities led to other social constructions of employee involvement as forms of influence, an Information-Influence Matrix, and the appropriateness of organizational arrangements. These interests developed to seek understanding at the level of the individuals involved using personal construct psychology (Kelly, 1955) and then into personal Frameworks of the individual and the organizational as perceived by an individual (Purdy, 1993).

The previous paper and earlier versions used the Information-Influence Matrix to demonstrate how the anticipated general changes in Galician healthcare might be handled by individuals. The changes indicated that a Health Centre Manager would be employed to run the Health Centre. Previously, a Health Centre had been administered by an Upper Manager so we anticipated that the Upper Manager would be involved helping the Health Centre Manager into the new situation. The paper demonstrated how changes in the individual managers might occur and it used the Information-Influence Matrix as a means through which to show and understand the changes (Purdy and Gago, 2003).

The components of the Matrix are constructs of information and influence relating to an employee and a manager. Each construct has four areas defined. With influence are the markers of No Influence, Communication, Consultation and Participation.

No Influence is the position where the employee is not allowed to exercise any influence in the organization in the formal sense, or perceives no obvious influence in the situation. An employee could influence matters by leaving the organization for example.

Communication is a position where the manager tells the employee about a decision already taken, for example, by the manager. The employee might have the opportunity to formally express an opinion about the decision, but cannot directly influence the situation because the decision was already taken.

Consultation is the position where the manager provides information to the employee about a situation, and the employee has an opportunity to express an opinion to the manager before the manager takes the decision. Here the employee could affect the manager's decision because of the discussion.

Participation is the position where the employee receives information about a situation and discusses this with the manager before they jointly take a decision, or take it in some manner which they jointly agreed previously. The employee has the most opportunity to influence a situation, and for participation to happen, the manager and employee have to interact. Any information can come from either person. 
Participation requires the employee to be an effective and active person capable of learning, as well as providing ideas and information. Information, influence and interaction all appear to be necessary for participation to be in a state to occur (Purdy and Gago, 2003).

Wall and Lischeron (1977) devised and tested their notion of decision distance in their work on participation. Employees in a participative situation had notions about the relative distance of decision-making from them. The closest distance decisions were "Local", such as the employee's immediate job decisions. Other decisions could be at a "Medium" distance from the employee and perhaps concern a department. The furthest decisions were called "Distant", and could concern decisions about the whole organization.

To conceptualise information, Purdy adapted the decision distance types of Wall and Lischeron (1977). Again there are four markers for each area, which are: No Information, Local Information, Medium Information and Distant Information.

No Information is the position where the employee perceives that no information is received or provided.

Local Information is that information which exists for the current and immediate job at hand. It is a local decision for the employee and likely to be the smallest quantity of information.

Medium Information is information for decisions further than the immediate job or the initial work activity. Decisions are taken at a medium distance from the employee and this information is likely to be more complex than local information.

Distant Information is any information used for decisions beyond medium decisions. Such decisions are taken at the furthest distance from the employee and probably use the most complex of information from any part of the organization.

\subsection{The Information-Influence Matrix}

The constructs of Information and Influence have been construed for use with an employee. Purdy considered that the constructs of Influence and Information were used at the same time, when an employee made decisions. To show this he used a Matrix as a method of representation and brought in the two constructs, each with the four areas and four markers defining these. This is the Information-Influence Matrix. After ascertaining the employee's arrangements for influence and information, Purdy indicated that, these details could be used by a researcher to determine the position of an employee on the Matrix in relation to information and influence. In this way it is possible to study the position and movement of an employee on the Matrix, which should be able to deal with any situation.

Fig. 1 is a representation of the Information-Influence Matrix for a hypothetical employee. Each person and context is anticipated to be different and each will act differently. The boxes for the same position of influence contain the same words, as these are only an indication of the employee's action.

We used the Information-Influence Matrix to anticipate what would happen, in general, with an Upper Manager and a Health Centre Manager. We also explained the history of our approach to research using Frameworks in job situations (Purdy and Gago, 2003). We accepted that organizations have differences in accounting systems, decision-making and change (Purdy and Gago, 2003) and the notions of George Kelly about personal construction (Kelly, 1955). Personal construction had been used to demonstrate the differences in ability 


\begin{tabular}{|c|c|c|c|c|}
\hline \multirow{2}{*}{$\begin{array}{l}\text { Information } \\
\text { constructs }\end{array}$} & \multicolumn{4}{|c|}{ Constructs of employee influence } \\
\hline & No influence & Communication & Consultation & Participation \\
\hline Distant & $\begin{array}{l}\text { Unique Health } \\
\text { Centre Manager's } \\
\text { reaction is outside } \\
\text { the formal } \\
\text { structure }\end{array}$ & $\begin{array}{l}\text { Unique Health } \\
\text { Centre Manager } \\
\text { expresses an } \\
\text { opinion about the } \\
\text { policy }\end{array}$ & $\begin{array}{l}\text { Unique Health } \\
\text { Centre Manager } \\
\text { and Upper } \\
\text { Manager discuss } \\
\text { before Upper } \\
\text { Manager makes } \\
\text { policy }\end{array}$ & $\begin{array}{l}\text { Unique Health } \\
\text { Centre Manager } \\
\text { and Upper } \\
\text { Manager } \\
\text { formulate policy }\end{array}$ \\
\hline Medium & $\begin{array}{l}\text { Unique Health } \\
\text { Centre Manager's } \\
\text { reaction is outside } \\
\text { the formal } \\
\text { structure }\end{array}$ & $\begin{array}{l}\text { Unique Health } \\
\text { Centre Manager } \\
\text { expresses an } \\
\text { opinion about the } \\
\text { policy }\end{array}$ & $\begin{array}{l}\text { Unique Health } \\
\text { Centre Manager } \\
\text { and Upper } \\
\text { Manager discuss } \\
\text { before Upper } \\
\text { Manager makes } \\
\text { policy }\end{array}$ & $\begin{array}{l}\text { Unique Health } \\
\text { Centre Manager } \\
\text { and Upper } \\
\text { Manager } \\
\text { formulate policy }\end{array}$ \\
\hline Local & $\begin{array}{l}\text { Unique Health } \\
\text { Centre Manager's } \\
\text { reaction is outside } \\
\text { the formal } \\
\text { structure }\end{array}$ & $\begin{array}{l}\text { Unique Health } \\
\text { Centre Manager } \\
\text { expresses an } \\
\text { opinion about the } \\
\text { policy }\end{array}$ & $\begin{array}{l}\text { Unique Health } \\
\text { Centre Manager } \\
\text { and Upper } \\
\text { Manager discuss } \\
\text { before Upper } \\
\text { Manager makes } \\
\text { policy }\end{array}$ & $\begin{array}{l}\text { Unique Health } \\
\text { Centre Manager } \\
\text { and Upper } \\
\text { Manager } \\
\text { formulate policy }\end{array}$ \\
\hline No information & $\begin{array}{l}\text { Unique Health } \\
\text { Centre Manager's } \\
\text { reaction is outside } \\
\text { the formal } \\
\text { structure and is } \\
\text { without formal } \\
\text { organization } \\
\text { information }\end{array}$ & & uations cannot exi & \\
\hline
\end{tabular}

Fig. 1. An Information-Influence Matrix.

of managers on one committee to understand accounting data. Purdy had used a Framework of Eight Issues, that he anticipated an individual Ward Unit Manager might possess, as the theoretical approach to his longitudinal study in a UK teaching hospital (Purdy, 1993).

In Purdy and Gago (2002), this Framework was subsequently revised, simplified and re-considered in a Spanish context to be used with research conversations with Business School managers. The work corroborated the useful and sensitive nature of the Original Framework and the dynamic nature of such Frameworks.

These methodological approaches using Frameworks and Matrices were adopted in the previous paper (Purdy and Gago, 2003). In that paper it was understood that the general nature of changes would be as follows. An Upper Manager and a Health Centre Manager would be involved in management changes at a Health Centre. The relevant general aspects 


\begin{tabular}{|c|c|c|c|c|}
\hline \multirow{2}{*}{$\begin{array}{l}\text { Information } \\
\text { constructs }\end{array}$} & \multicolumn{4}{|c|}{ Constructs of employee influence } \\
\hline & No influence & Communication & Consultation & Participation \\
\hline Distant & $\begin{array}{l}\text { Unique Health } \\
\text { Centre Manager's } \\
\text { reaction is outside } \\
\text { the formal } \\
\text { structure }\end{array}$ & $\begin{array}{c}\text { Unique Health } \\
\text { Centre Manager } \\
\text { expresses an } \\
\text { opinion about the } \\
\text { policy }\end{array}$ & $\begin{array}{l}\text { Unique Health } \\
\text { Centre Manager } \\
\text { and Upper } \\
\text { Manager discuss } \\
\text { before Upper } \\
\text { Manager makes } \\
\text { policy }\end{array}$ & $\begin{array}{l}\text { Unique Health } \\
\text { Centre Manager } \\
\text { and Upper } \\
\text { Manager } \\
\text { formulate policy }\end{array}$ \\
\hline Medium & $\begin{array}{l}\text { Unique Health } \\
\text { Centre Manager's } \\
\text { reaction is outside } \\
\text { the formal } \\
\text { structure }\end{array}$ & $\begin{array}{c}\text { Unique Health } \\
\text { Centre Manager } \\
\text { expresses an } \\
\text { opinion about the } \\
\text { policy }\end{array}$ & $\begin{array}{l}\text { Unique Health } \\
\text { Centre Manager } \\
\text { and Upper } \\
\text { Manager discuss } \\
\text { before Upper } \\
\text { Manager makes } \\
\text { policy }\end{array}$ & $\begin{array}{l}\text { Unique Health } \\
\text { Centre Manager } \\
\text { and Upper } \\
\text { Manager } \\
\text { formulate policy }\end{array}$ \\
\hline Local & $\begin{array}{l}\text { Unique Health } \\
\text { Centre Manager's } \\
\text { reaction is outside } \\
\text { the formal } \\
\text { structure }\end{array}$ & $\begin{array}{l}\text { Unique Health } \\
\text { Centre Manager } \\
\text { expresses an } \\
\text { opinion about the } \\
\text { policy }\end{array}$ & $\begin{array}{l}\text { Unique Health } \\
\text { Centre Manager } \\
\text { and Upper } \\
\text { Manager discuss } \\
\text { before Upper } \\
\text { Manager makes } \\
\text { policy }\end{array}$ & $\begin{array}{l}\text { Unique Health } \\
\text { Centre Manager } \\
\text { and Upper } \\
\text { Manager } \\
\text { formulate policy }\end{array}$ \\
\hline No information & $\begin{array}{l}\text { Unique Health } \\
\text { Centre Manager's } \\
\text { reaction is outside } \\
\text { the formal struc- } \\
\text { ture and is without } \\
\text { formal organization } \\
\text { information }\end{array}$ & & uations cannot exi & \\
\hline
\end{tabular}

Fig. 2. Line represents anticipations about changes in the Health Centre Manager's position on the Matrix.

were that the Health Centre Manager would gradually take over the financial management and this aspect of control of a Health Centre from an Upper Manager who was currently doing that job.

\subsection{Specification of Initial Frameworks}

The personal Matrices were anticipated to change. The changes for the Health Centre Manager were anticipated and a line representing these anticipated changes is in diagram form in Fig. 2.

These anticipations were also constructed as a Framework of Issues for the Health Centre Manager on a Personal Matrix as follows: 
1. Starts in the No Information-No Influence box.

2. After a short period of time will interact with the Upper Manager and so will then be located in the Local Information-Communication box.

3. After a further period of interaction will be located in the Local Information-Consultation box.

4. After a further period of interaction will be located in the Local Information-Sole Participation box.

Also, a Framework of Issues on a Personal Matrix for the Upper Manager was also constructed as follows:

1. Starts in the Local Information-Sole Participation box.

2. After a short period of time will interact with the Health Centre Manager and so will then be located in the Local Information-Consultation box.

3. After a further period of interaction will be located in the Local InformationCommunication box.

4. After a further period of interaction will be located in the Local Information-Different Information box.

These Initial Frameworks are re-considered after a more detailed analysis of our understandings about likely activity in Galicia. The next section explains the Galician background in terms of legal matters and healthcare expectations.

\section{Galician Context}

\subsection{Legal matters}

Since 1978, the Spanish Constitution has recognised and guaranteed the right of autonomy to Spanish nationalities and regions (Constitución Española, 1978, p. 2). Spain is composed of seventeen autonomous communities, two departmental communities (Balearics and Canary Islands) and two autonomous cities (Ceuta and Melilla).

The autonomous communities may assume responsibility for and control of healthcare (Constitución Española, 1978, p. 148). The Government exerts control over all healthcare in Spain. It determines the basis and general co-ordination of healthcare, regulates medicines through statutes, and passes basic legislation dealing with healthcare and its funding through the system of Social Security (Constitución Española, 1978, p. 149). The Government can delegate its responsibilities and control to any of the autonomous regions (Constitución Española, 1978, p. 150).

Since 1981 the Spanish Government has decentralised a wide range of healthcare matters to Galicia, one of its autonomous regions. The Galician Government has the right to determine many aspects of healthcare. It can organise and administer its own healthcare and to legislate for these (Article 33 of the Ley Orgánica, 1/1981). However, it cannot legislate for the financing of healthcare as funds come from the Spanish Government. Fig. 3 lists the main relevant legal and institutional changes about Galician healthcare between 1978 and 1998.

The Galician Health Service (SERGAS) was created in 1989 to improve and achieve a higher level of health amongst Galicians (Ley, 1/1989). Primary healthcare is the first level. 


\begin{tabular}{|l|l|}
\hline YEAR & MATTER OF THE LAW \\
\hline 1978 & $\begin{array}{l}\text { The Government may delegate its responsibilities and control over } \\
\text { matters in the autonomous regions }\end{array}$ \\
\hline 1981 & $\begin{array}{l}\text { Spanish Government decentralised a wide range of healthcare matters } \\
\text { to Galicia }\end{array}$ \\
\hline 1989 & Creation of the Galician Health Service \\
\hline 1993 & System of participative management \\
\hline 1995 & $\begin{array}{l}\text { Galician Government organises the upper management of primary } \\
\text { healthcare into five areas }\end{array}$ \\
\hline 1996 & Existing personnel are offered the opportunity to join the new system \\
\hline 1998 & Structure for offering primary healthcare services \\
\hline
\end{tabular}

Fig. 3. Main legal and institutional changes relating to Galician healthcare (1978-1998).

It is based upon the traditional trust between doctor and patient. Primary healthcare, being the prevention of illness, individual and group health education, social work in the health area and any other community groups concerned with health matters, will generally be based upon a Health Centre. Various laws have contributed to the modernisation of primary healthcare in Galicia. These aim to achieve a level of primary healthcare, which fulfils not only health criteria (high quality, respect for the patient, etc.) but also management criteria.

In 1993 the Decree (Decreto, 200/1993) for the modernisation of primary healthcare was issued, indicating substantial changes for healthcare, its organization, the use of resources and its development. The intended changes were the outcome of a study and consensus with the territorial corporations who had to participate in the formulation of health policy according to Spanish law. Territorial corporations include representatives from trade unions and business' associations. This process must maintain the required representative proportions as guaranteed by Spanish law (Ley Orgánica, 11/1985, p. III; Ley, 14/1986, p. 5).

The 1993 Decree required not only high quality healthcare but also the need for easy access to a Primary Healthcare Unit, i.e. a Health Centre. Health Centres were required to be suitably located and to function with appropriate demographic ratios and types of care. The Decree expected unity to be promoted among the different healthcare professionals. Each Health Centre was free to provide a variety of advertised services, although there was a minimum group of activities common to all centres.

The Primary Healthcare System and Health Centre were expected to facilitate the real and effective participation of the immediate community so as to achieve the objectives of primary healthcare given by law (Decreto, 200/1993).

All primary healthcare was to be promoted within a system of participative management based on the objectives set and evaluated by the results attained. The 1993 Decree did not mention definite outcomes or key performance indicators. It made a declaration of intentions about healthcare, but was conscious that the reform would require a certain amount of time and economic support, both of which were not available currently. 
This modernisation was expected to promote a climate in which professionals not only had a suitable environment and adequate conditions for developing their tasks, but also had incentives for remunerating those people who worked more, better, and were able to assume different "retos". Retos is a Spanish word without a direct English equivalent, and is explained further in the main section Observations on Galician Background (see p. 11). The law stated that information management systems would capture information about individuals and the definite objectives that they achieved successfully in a period of time.

The individuals were to be rewarded with a productivity bonus for their additional effort to achieve continuous improvement. The development of a suitable management information system capable of producing information about individuals and their objectives was also expected to occur (Decreto, 200/1993).

The Decree's other objectives were the introduction of a health identity card, and the introduction of changes to the remuneration system, which took into account the number of patients and their characteristics-age, dispersion, etc. It was anticipated that there would be enough physical, human and permanent training resources available for these activities.

The Health Centre would be staffed with medical, nursing, non-healthcare and general service people. The working day would take into consideration the healthcare needs of the professionals involved, and a reasonable distribution of resources and workloads (Decreto, 200/1993).

The professionals would have a suitable environment and the opportunity to change their roles. Professionals would keep up-to-date with their knowledge. The Centre would have adequate technical support for health education, promotion and assistance, all set in the community and supported by legal and administrative functions (Decreto, 200/1993).

In 1995, the upper management of Galician primary healthcare was organised into five areas: A Coruña-Ferrol, Santiago de Compostela, Lugo, Ourense and Pontevedra-Vigo. Cities are grouped according to geographical and population criteria (Decreto, 252/1994; Orden 11 Mayo, 1995). The rest of this section of the paper relates to this Decreto and Orden unless shown otherwise.

These documents noted that an Upper Senior Manager was responsible for each area. He guaranteed the adequate development of the services in the area, as well as managing, co-ordinating, supervising and evaluating the activities. The Upper Senior Manager was responsible for adopting measures to achieve the Galician Government's objectives and for the other proposals aimed at achieving these objectives. Also, he managed human and economic resources, set out details of the proposed annual expenditures, produced periodic reports and an annual report about activities. Finally, he produced and submitted data about healthcare management to the Galician Government.

Directly responsible to the Upper Senior Manager were two individuals, a Health Manager and a Financial Manager. Our simplified notions about these managers and their relationships to a Health Centre Manager are shown in Fig. 4. This structure means a separation of the medical and administrative functions.

The Health Manager was responsible for managing, co-ordinating, supervising and evaluating the services of primary healthcare and the management of its implementation. $\mathrm{He}$ collaborated with the development of the services offered by the Health Centre and evaluated the quality of healthcare. He also took the position of the Upper Senior Manager in case of that manager's illness, absence, etc., and for the delegated functions specified by 


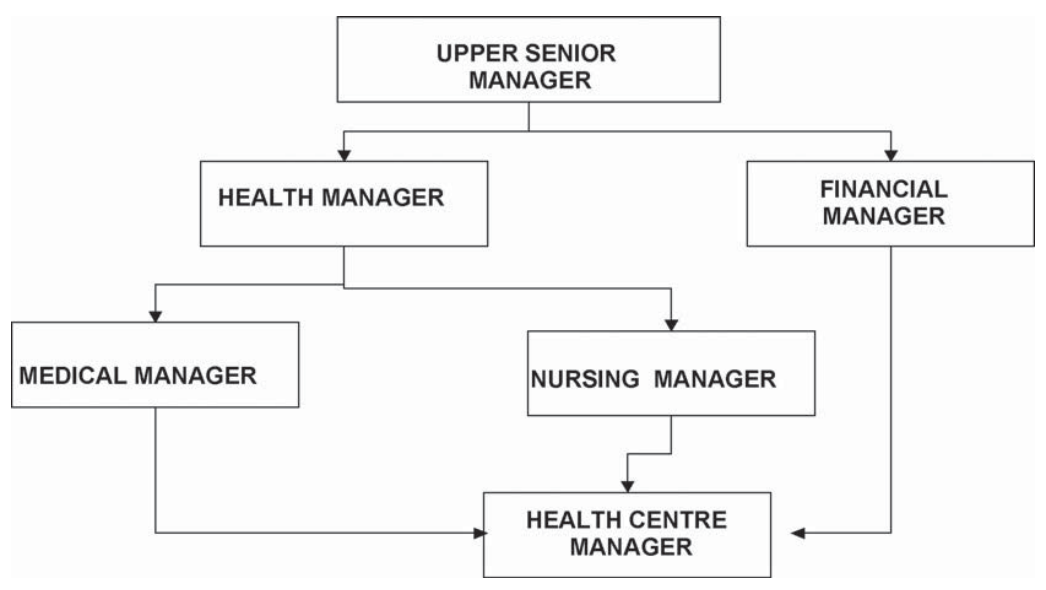

Fig. 4. Generalized management structure to a Health Centre Manager.

law. Subordinate to the Health Manager was a Medical Manager and a Nursing Manager, who were responsible for the management, co-ordination and supervision of the medical and nursing activities and for the delegated functions. These three managers are not a part of our research.

The Financial Manager was responsible for managing, co-ordinating and supervising the economic-administrative activity. He also provided administrative-technical support to other managerial levels and managed human resources. The Financial Manager gave technical-administrative support for producing the annual proposed expenditures, managed generally, co-ordinated, supervised and evaluated the areas that supported the healthcare activity, such as maintenance, cleaning, security, etc. He replaced the Upper Senior Manager in case of illness, absence, etc., when the Health Manager was not available to act for the Upper Senior Manager, and for the delegated non-healthcare functions. He had subordinates such as an Assistant Financial Manager.

The functions of all these levels of management in the Primary Healthcare Service were to provide, develop and evaluate primary healthcare. This included the establishment of annual objectives. The Head of the Primary Healthcare Service was responsible for co-ordinating the work of the Health Centres.

A 1996 Decree modified aspects of the 1993 Decree (Decreto, 161/1996). It offered existing personnel the opportunity to join the new system. In the new system, people would not earn less than before, but any promotion would not carry an increase in salary until that point when pay in the new system exceeded the old. There were provisions for doctors who did not want to enter the new system (Decreto, 226/1996).

A national law regulated the remuneration of those employed in Primary Healthcare (Real Decreto Ley, 3/1987). Thus, changes to the remuneration system took into consideration the types of people treated and the health characteristics of the Centre's population, so these factors had a more direct impact upon remuneration (Decreto, 226/1996).

In 1998, the system for offering primary healthcare was set out (Decreto, 352/1998). It proposed working through a Health Centre established in each municipality. A Health 
Centre Manager would be responsible for the Health Centre's functioning and organization to the Head of the Primary Healthcare Service. The Health Centre Manager was expected to allocate tasks and responsibilities, plan and run the service, and some of these would be full-time administrators (Decreto, 352/1998).

\section{Observations on the Galician Context}

\subsection{General}

These observations about the Galician legal context are the matters we consider important in relation to our empirical work and its analysis. Spanish healthcare was organized on a national basis so some healthcare policies and all funding came from the national government, consequently, Galician healthcare was related to these policies and the national funds provided. The Galician managers had responsibility and control of healthcare at the operational level but had to work with the national position, and any policy changes. In this paper we concentrate on the relationship between a Health Centre Manager and a Financial Manager.

The legislation indicated that there was to be a high level of healthcare based upon participative management. Amongst other things this participative management required a consideration of the policies of the Health Centre and related matters, to be made by a group of people who did not work in either the Health Centre or in the upper management functions above the Health Centre. These were the territorial corporations. Unless this group of people were involved in a sensible way with policy matters, any perceived inadequacies could be possible sources of problems for the Financial Manager and Health Centre Manager.

The legislation indicated that the minimum levels of healthcare were expected to continue, even though modernisation was expected to occur without the necessary time and necessary money required. The working day needed to consider the health professionals with a reasonable workload and adequate technical support.

This modernisation was expected to provide primary healthcare in a suitable environment, together with adequate conditions and incentives to remunerate people who were able to assume different retos. Retos is without direct translation into English, and appears to be more than a challenge. It is when a person struggles to achieve something, recognises the difficulties of trying to achieve this and learns from the experience. Retos contains the notion that in carrying out the actions towards its achievement there is self-improvement for the person.

Our interpretation of Retos for this context is as follows. Retos relates to an area of activity where the area's objective is difficult to develop or carry out. For these reasons the retos constitutes a stimulus for the people who are trying to work in that area. A Retos is somewhat intangible and a qualitative developmental aspect of life.

The law stated that future information management systems would capture information about individuals and the definite objectives that they achieved (successfully) in a period of time. Also, individuals would be rewarded with a productivity bonus for their additional effort to achieve continuous improvements. It was not clear how the objectives would be determined and implemented, especially when a retos was an area that was difficult to be 
precise about. These matters were likely to be problematic with the individuals involved in the changes.

In our view a similar problem could occur with the reforms which remunerated those in primary care in line with the population they cared for. For example, although an individual may not lose any remuneration when moving to another job as a part of the reforms, there was also no possibility that the individual's remuneration could move beyond the new remuneration structure set out by Spanish law. Consequently, under these conditions an individual would not be able to increase the amount of their remuneration even though they took part in the reforms, or achieved a definite objective, or were promoted.

In line with the Galician expectations, it was anticipated that to aid change in any of these areas, people would receive various forms of assistance such as counselling and training. Our anticipations about the effects of the possible changes for a Financial Manager and a Health Centre Manager are next.

\subsection{Financial Manager}

The material above indicates that a Financial Manager had a wide range of duties and responsibilities including producing the annual proposed expenditures and general support of healthcare activities. It indicated that this manager's influence over a Health Centre's affairs was quite considerable. This could continue even after a Health Centre Manager had been put in place and was running the Health Centre.

On the appointment of a Health Centre Manager, one objective would be that in time he would take full responsibility for the Health Centre, in place of the Financial Manager. As the Health Centre Manager took responsibility so the Financial Manager would no longer have sole responsibility and would move to a position of less influence over the Health Centre at a daily level.

In the current position at the start, the Financial Manager would appear to have sole responsibility for the Health Centre receiving all information about it and taking all the decisions about daily activities. In this way the Financial Manager appears to act with autonomy about daily activities. Over time this autonomy over decisions passes to the Health Centre Manager. One reason for using the word autonomy is because Galicia is an Autonomous Regional Government of Spain. Also, the healthcare reforms of the Galician legislation suggest forms of autonomy. In this way the type of influence that the Financial Manager had is anticipated to change from daily running responsibility to some other responsibility, such as longer term plans about the Health Centre.

It was anticipated that the Health Centre Manager would take responsibility gradually, and at the same time he was anticipated to be a source of information for the Financial Manager. For example, if the responsibility for dressings had moved to the Health Centre Manager the Financial Manager might now only be interested in total costs and usage. We can anticipate that there will be this type of "Health Centre Manager local information" created by the Health Centre Manager but we cannot make any anticipations about how this is regarded by the Financial Manager. It seems like Local information for the Financial Manager.

The notion of participative management was not defined by the legislation. We consider it to be a notion that we anticipate to vary with each Financial Manager and each Health 
Centre Manager. The ways in which participative management is interpreted and handled by the Financial Manager and the ways in which it is interpreted and handled by the Health Centre Manager might not be similar and might cause problems.

Another area where there could be difficulties is with retos. We anticipate the Financial Manager to be responsible for the introduction of any number of retos with a Health Centre Manager, and, as indicated above, these might not be easy to devise and implement. This Financial Manager also appears to be responsible for the management system that produces information about the retos. We also note that the Financial Manager might have retos too.

\subsection{Health Centre Manager}

With the proposed changes the Health Centre Manager would become responsible for the functioning and organization of the Health Centre, and presumably the prime person entrusted with the development of the Health Centre within its community. Depending upon the previous functioning of the Health Centre, these jobs could range from being quite straightforward to quite complex.

An individual taking up the position of a Health Centre Manager would need to be content to carry out the particular jobs that the Financial Manager wants done. Also, the establishment of the jobs could be a part of the participative management and subject to negotiation. Clearly the previous work background and training of the Health Centre Manager will be relevant to how matters develop. The issues of remuneration and the ways in which various retos are devised and implemented could be large concerns for the potential Health Centre Manager.

Amongst other things, we anticipate the Health Centre Manager will be involved with the acquisition of knowledge about the Health Centre and its financial affairs. Assuming that the person starts with limited knowledge about the Health Centre's affairs, including the financial aspects, it is anticipated that any Health Centre Manager in this position will learn these. This learning could occur in the course of the work at the Health Centre and with the Financial Manager's assistance. There could be other types of training.

As the Health Centre Manager learns so he will start to exercise influence over the Health Centre's affairs, and should take increasing amounts of responsibility for the Health Centre. In this way the Health Centre Manager will become more independent about running the Health Centre, until he has the responsibility to do this essentially on his own. We anticipate that the Health Centre Manager will take over the autonomous decisions previously made by the Financial Manager and will achieve autonomy with the Health Centre.

As the Health Centre Manager becomes autonomous we anticipate that he will create suitable information for a report to the Financial Manager. This information will relate to the Health Centre and it is anticipated to be Local information for the Health Centre Manager.

\subsubsection{Some UK evidence}

The Galician proposals for greater participation and information provision in the management of health centres may be very different to previous Galician ideas, but there had been somewhat familiar, if not similar, UK discussions in the 1970s and 1980s.

The national political context was that there had been industrial unrest in the 1970s. Some trade unions had claimed that companies could afford more pay for their employees and 
had used the company's annual accounts as one basis for the argument. In return companies claimed they could not afford more pay, indicated low company profits and there was a general move from more companies to make a copy of their annual report available to their employees. Conservative and Labour governments wanted to make to these reports formally available to employees.

Labour governments went further and proposed giving employees the same legal rights to receive a copy of the annual report as shareholders (Department of Trade, 1977a). There were also proposals for employee representatives to sit on the company boards of directors (Department of Trade, 1977b) and therefore it was considered that these reports should be seen as a part of a move for employees to enter into the running of companies and the wider concerns of industrial democracy (The Prime Minister, 1978).

The Labour governments encouraged industrial democracy by suggesting union representatives should experience life at the board of directors' level of the nationalised steel company in the early 1970s (Brannen et al., 1976) and the Post Office in 1978 (Batstone et al., 1983). These experiences stopped in both areas, but these movements had undoubtedly influenced the general UK climate about information provision and employee involvement, as well as the production of an Employee Report (Purdy, 1988).

There were a few contemporary UK studies which related to the provision of accounting information. Here some studies concerned with management accounting information and or management information in more general are examined. The Tavistock Institute's Centre for Decision-Making Studies conducted 36 in-depth interviews with key people, who had particular knowledge of company affairs such as managers, supervisors and employee representatives, in four banks/insurance and six metal manufacturing companies. These interviews covered the reasons for and the extent of information provision to employees and the methods these companies used to provide this information (Centre for DecisionMaking Studies, 1979).

Twenty-four shop-floor employees completed a questionnaire to enable the researchers to examine the impact of information provision on these employees and to assess the facilitators or constraints on information provision. The results indicated that management controlled the information provision process from the outset. Companies were more responsive to providing information about matters of recent legislative interest, such as health and safety and pensions. In all of these companies the least used form of information flow to the shop-floor employees was through the immediate supervisors (Centre for Decision-Making Studies, 1979). It was later observed that these findings indicated an absence of processes which might have fostered employee involvement (Purdy, 1988).

A notion of employee involvement was crucial to Goodlad's project to assess, if it would be viable to develop and monitor budgets from co-operation between management and non-management employees, and, if this co-operation contributed to improved industrial relations. Goodlad's (1984) view was that information provision to employees could only be meaningful in partnership with managers, employees and shareholders, and, that the management accountant should serve all three.

Goodlad's study was to involve six major UK companies, who had agreed to work with him and provide case materials. He started initial work, progressed only a little further and the study was not completed. He found no company had non-management employee involvement in budgets, only one had considered it, and thought that senior management 
was concerned with its own self-protection (Goodlad, 1984). It was noted that Goodlad had created interest in his ideas amongst his professional management accounting colleagues at lower and middle-management levels, about his notion to involve non-management employees in budgeting, but senior management had prevented this from happening and so retained its power over a company's future (Purdy, 1988).

A study by Marsh and Hussey involved the use of completed questionnaires from 236 companies. One hundred and ninety nine (84\%) companies considered their principal reason for providing an Employee Report was to involve their employees in company affairs (Marsh and Hussey, 1979). As their analysis was deficient Reeves classified their results to obtain clarification (Reeves, 1980). Unfortunately, he still failed to demonstrate how this provision of an Employee Report in isolation would bring about the stated aim of employee involvement (Purdy, 1988).

In a study of the reporting practices of some of the largest UK public companies in the late 1970s, Purdy interviewed the directors and senior managers. He wanted to identify

(a) why these companies had provided their employees with financial information,

(b) the means through which each company achieved this provision,

(c) the degree of information provision (or disclosure) to which each company was committed.

The responses enabled the company management to be classed as either "traditional" or "non-traditional" reporters of financial information to employees. The traditional reporting companies had an "open" management style of financial information provision to employees. These "open" companies also had the highest degree of unionisation with the possibility that the presence associated with the unions had related to this "open" style. The open information companies had operational structures such as works councils and briefing groups where managers and employees met and exchanged views and information. The open companies primarily provided operational information through the management structure. The Employee Reports had emerged on the initiative of management and were not a response to requests for them (Purdy, 1988).

The "non-open" companies had the lowest levels of unionisation and a general absence of systems through which management were aware of employee's views. These companies were trying to foster the notion to employees that they were open in their approach to information provision, their employees were treated fairly and so had produced an Employee Report to show this (Purdy, 1988).

These two styles indicated different degrees of management provision (or disclosure) of financial information. In open management companies, the employees received verbal operational financial information and notionally could request and receive any piecemeal information, as well as receiving an Employee Report. In the non-open management companies the employees only received an Employee Report they did not receive operational information nor could ask for piecemeal information. The interviewees from both styles were more prepared to provide information to union representatives than to employees (Purdy, 1988).

A subsequent review of these findings suggested that open management companies were using an approach to information provision that could very easily be restricted if senior management chose to refuse to provide piecemeal information requested by employees. The 
review of previous research in this area concluded that management had used accounting data to sustain its power position. Further, there were inadequate conceptualisations of research in this area. Currently, senior management controlled the context, the content and the boundaries of financial information. There was a need to consider financial information simultaneously with notions of influence and power. There was a need for a research approach that recognised a continuum of accounting information rather than a consideration of discrete amounts of information. The provision of financial information needed to be appropriate for each situation and to consider how the information is received by the employee (Purdy, 1988). The conceptualisation of the Information-Influence Matrix was one response to such matters.

\subsubsection{General European Economic Community views on information provision and employee involvement}

The national political UK events about employee information provision and employee involvement were paralleled in some ways with various activities in the European Economic Community. Not all of the Commission's materials are included or discussed here because this is background material. It should be noted, however, that there were discussions nationally in the UK governments about these proposals, but it was not until the Labour government of 1997, that a UK government then ratified in December 1997 what had previously been accepted by all of the other members of the Community, including Spain. The founding document (Treaty of Rome 1957) of the Community in Article 118b noted its Commission shall endeavour to develop a dialogue between management and labour at the European level which could, if both sides considered it desirable, lead to relations based on agreement (European Economic Community, 1987).

The Commission, then, had been studying such matters since 1957 and had made unsuccessful proposals about information provision to employees and employee participation and consultation. The first draft was issued in 1975 (European Communities Commission, 1975), it was revised in 1980 (when it was known as the Vredling Directive). The draft was expected to apply to transnational companies with more than 1000 employees and proposed three main rights for employees.

(a) Annual information from the parent undertaking about employment showing parent and subsidiaries.

(b) Details about the parent's proposals liable to have serious consequences for employees in subsidiaries being expansions or contractions.

(c) Consultation over any such proposals and to delay them at least 30 days after the opening of consultation (European Communities Commission, 1980).

In May 1989, these matters were re-formulated in the Commission's Community Charter of Fundamental Social Rights (referred to as the Social Charter), and accepted in December 1989. There were 12 sections including one, "Right to information, consultation and participation of workers", noting that the provision of information, consultation and participation for employees shall be developed in a manner appropriate for laws, practices and contractual agreements in member states. These rights were to cover technological changes bankruptcies, redundancies mergers, restructuring and any major changes with implications for employees' employment (European Communities Commission, 1989). 
In September 1994, the European Works Council Directive was issued. Its objective was to improve the rights of employees to information and consultation in organizations with more than 1000 employees. Organizations had to establish either a works council or a procedure for informing and consulting employees. Consultation was the exchange of views between employees' representatives and central/appropriate management. The information component covered the organization's structure, economic/financial situation, probable development of business, production and sales, employment situation and trends, investment, any substantial changes concerning the organization including new work methods (European Communities Commission, 1994). In March 2002, the Commission issued a Directive to cover all other organizations to consult and inform their employees. This could take different types of forum to the works council, such as directly with employees or indirectly through their representatives. Those with more than 150 employees had to commence a forum from April 2005, whilst the smallest with more than 50 employees will start after April 2008 (European Communities Commission, 2002).

It is of note that the sporadic references in Commission documents to the notion of participation by employees and directly introduced by the Social Charter in May 1989 had formally disappeared by September 1994.

\subsubsection{Some US evidence}

We have selected some of the US literature in the accounting area. Dewhirst considered communication channel utilization and indicated that interpersonal channels involved a "psychological cost" for individuals who were not used to sharing information. In a study of engineers and scientists he found that the most appropriate communication channels were influenced by an individual's perceptions of the organization's information-sharing norms. He found, however, that the norms of the management in the work division of an individual could affect the perceptions of that individual. In divisions with the norm of using interpersonal channels of communication were perceived, the more the interpersonal channels were used and the less use was made of the written channels (Dewhirst, 1971).

A study of the boundary role person considered his influence and potential ability to influence decisions of other organization members. The boundary role person influenced the organization's members through his expert power and was able to channel and control information-sharing into the organization (Spekman, 1979).

In a study which considered management teams and their performance measures to improve the organization's response, Scott and Teissen found that successful teams were the ones whose members had the suitable abilities, were empowered and had adequate information, and were rewarded for their performance. The team's performance was positively associated with the variety of measures used and the performance increased when members took part in setting the performance target. Team performance increased in teams where there was greater weight given to their compensation. Teams performed better when members participated in setting the measurement targets and received more compensation (Scott and Tiessen, 1999).

Parker and Kyj examined vertical information sharing between managers and supervisors in the budget process, with responses from 70 people in US manufacturing. They found vertical information-sharing important to understanding budget participation and organizational commitment. Information sharing occurred after organizational commitment and 
budget participation were in place, whilst the organizational commitment and budget participation were affected by role ambiguity. Job performance, organizational commitment and information haring were linked (Parker and Kyj, 2006).

The most relevant US study here was Arnold's critique of 3 US companies' new manufacturing and accounting regimes using some labour movement debates of the 1980s and 1990s. By the late 1980s, the three companies had adopted employee participation programmes which seemed textbook models of employee involvement. In the 1990s, however, the companies had bitter labour disputes. In one company the unionists were disillusioned with the "empowerment" rhetoric, when they found the reality was outsourcing, downsizing and concessions on job conditions. Trust was destroyed and made worse when people were locked out or replaced. Those who embraced union/management co-operation were sceptical of participation programmes, teams and quality circles. Arnold (1999) thought the employee participation schemes were to the same end as scientific management practices, namely to control labour with standards.

At a second company the work was intensified. Some employees had more responsibilities without pay. Some had less autonomy over their work and some had more autonomy, but for those with more autonomy it was short-lived. There were a variety of explanations about the demise of autonomy. Some thought it had gone because the management had changed. Some thought that if the management's future union negotiations were unsuccessful, then the management would be unable to cope in an autonomous situation. Some felt that management had been insincere and had used employee involvement to appropriate their knowledge and weaken the unions. Management had presented employee involvement and co-operation as a universal truth and excluded other views from discussion. Arnold (1999) concluded that the employee involvement had not provided the promised empowerment, job security and workplace autonomy, but it had provided the opposite with intensified Taylorism, job reductions and permanent replacements.

\subsubsection{Summary}

The evidence from studies from the UK, the European Community and the US suggest that moves towards the notions of employee involvement and information provision are presented in very positive and strong ways, and accompanied by assurances of a more fruitful or creative future for those involved. This seems to work at a management level in the UK and US, but not at the lower levels of employees with autonomy and employee involvement. In the European Community the elusive notion of employee participation was held out, only to be removed for employees.

\section{Critical comments on the Galician Context and similar changes elsewhere}

The previous section clarified the Galician legal context then indicated that this paper would accept these notions at face value and these notions are implemented in the next main section. Before dealing with these implications, it is appropriate to explain the bases of why we have accepted these legal proposals for change at face value and which norms we consider underlie our acceptance. We then introduce some previous literatures to provide some evidence of changes which are in a similar area, from elsewhere. These suggest 
that the Galician changes will not occur smoothly. A second sub-section contains a brief critical commentary containing previous research and reviews from the UK. A third deals with European Community proposals for informing and involving employees. The fourth presents some materials from the U.S. literature.

\subsection{Underlying norms}

At the start of this research we sought the help of the Galician Health Service and were given access to a financial manager who was expected to follow and implement these Galician laws in accordance with the Health Service's norms. This financial manager agreed to provide empirical materials about the progress of change, as well as access to some of the clinicians involved. At the initial meeting with the financial manager he indicated clearly the importance of the Galician-inspired changes that he could bring to Galician healthcare. He was very enthusiastic about his work, the imminent changes and clearly considered the whole prospects for the Galician region in a very positive way and its healthcare proposals a Galician initiative. We chose to accept his optimistic view about change without evidence to the contrary.

The authors have different nationalities and experiences which did not lead to a straightforward acceptance about adopting this position. The Galician identity is strong with a language more in common with Portuguese than Spanish as well as newspapers, books and TV, all of which are widely accepted throughout Galicia. Having agreed our position, however, it meant that we had adopted the badges of a Galician identity attached to those laws. The section on the Galician context showed that Galicia had been recognised as a separate Spanish region and identity with the opportunity to take responsibility and control of healthcare since 1978 (Constitución Española, 1978, p. 149). In 1981, the Spanish Government decentralised to the Galician Government the right to organize, administer and legislate for these matters (Article 33, Ley Orgánica, 1/1981). The Galician Government, however, was never provided with the power to legislate to collect finance for Galician healthcare, and the Spanish Government continuously determined the general co-ordination of healthcare in Spain.

The Galician Health Service had been created in 1989 and various Galician laws since had highlighted the need for primary healthcare based on health centres. The 1993 Galician Decree stated the need for the modernisation of primary healthcare with suitably located health centres providing a range of facilities in conjunction with the real and effective participation of the immediate community. The healthcare provision was to be made available through a system of participative management based on the objectives set and evaluated by results, however, both the time and the funds for this were currently not available (Decreto, 200/1993).

Without repetition of all previous materials, these laws were proposals consistent with notions of Galicianization and localization of the improved provision of healthcare. These Galician laws indicated reforms specifically for the Galician region. This promoted an acceptance and an affinity to these proposals which allowed the financial manager and the authors to adopt this acceptance.

These laws were statements about anticipated and desirable healthcare norms in Galicia at some future point, as they accepted there were no resources of time and money. This could 
be a characteristic of Galicia, as it was once considered an independent set of people on one northern border of Spain that was not easily accessible from Madrid and other Spanish cities.

The Galician laws did not state particular outcomes or indicators for the work. It did expect the health professionals to work in suitable conditions for the development of their work, with appropriate remuneration incentives for those who worked more, worked better and assumed different "retos". There would be productivity bonuses for the additional effort of continuous improvement (Decreto, 200/1993).

In 1996, the existing health centre staff were offered a new system where doctors could not earn less than before, but they could only acquire a salary increase if on the new system salary exceeded the old. A new remuneration system incorporated the characteristics of the health centre population and the types of people treated. (Decreto, 226/1996). The remuneration of those employed in primary healthcare was nationally regulated (Real Decreto Ley, 3/1987).

Again the laws outlined desirable working conditions for the staff, but a local remuneration policy for the doctors seemed an impossibility because their remuneration was and is set nationally and, therefore, it is difficult to conceive of changes about remuneration.

Was it possible that the reference to retos was a Spanish narrative that attempted to appeal to the doctors to change their work routines without payment? We have interpreted retos as an activity area where the object is difficult to develop or achieve. It is also a stimulus for people trying to work in an area, and, it is also an intangible and qualitative developmental aspect of life. It might be that the law has offered the doctors personal development instead of resources and remuneration.

The notions of autonomy in the context of all Spanish regions, including Galicia, has been important from the start of modern Government in Spain.

Autonomy occurs for any individual as a personal response at the national and regional levels, as well as the organizational level. There has been the desire for autonomy in Spanish life so that the idea of autonomous health centres would be appealing. The inter-connection between regionally based Galician laws, the notion of local identity formed with Galicia, the ability to take part and participate in affairs all imply some personal freedom, and this is reinforced with notions of freedom covered by autonomy.

These all amount to the potential health centre manager being placed in a position of autonomy, defined as a part of joint-decision taking and then sole decision taking. The underlying norms identified are a part of the overall narrative about regional freedom in Spain, and portrayed in Galician laws. These and other narratives about Galicia have produced personal constructs in the authors and the financial manager about the Galician identity and wanting the changes in the Galicia region to succeed.

\section{Implications for the Framework for individuals}

We have selected some of these more detailed materials relating to the possible individuals involved, which might be relevant to our research. The legislation has stated only in general terms the need for a Health Centre Manager and that this person will work with the Financial Manager in running the Health Centre. Legislation has not indicated specific issues beyond this or how the changes towards the participative management of Health 
Centres were to occur. We anticipate that the Galician Health Service might provide advice and suggest how change is to occur, or it might be left to the Financial Manager to arrange, or be a combination of both.

The paper now considers influence and information in relation to the Framework of Issues on a Personal Information Influence Matrix for the Financial Manager and the Health Centre Manager. Influence is dealt with first.

\subsection{Influence}

When Purdy considered influence as a construct/notion of No Influence to Total Influence, he chose not to use Total Influence as a marker in the Information-Influence Matrix. If the Financial Manager is responsible for the Health Centre, does this imply that he has Total Influence over the Health Centre and that the Health Centre Manager will eventually also have this?

Total Influence does not seem an appropriate influence marker to use after the legal and institutional changes. Total influence by one manager does not seem to apply to Galician healthcare where it seems that matters are discussed before decisions are taken by the managers. Further, we have no knowledge of people who claim to have Total Influence over matters in a participative system. We started with the construct No Influence to Sole Participation in the Initial Frameworks.

The Information-Influence Matrix has an influence construct marker of Participation, where two people can bring forward information before they jointly make a decision. This consideration of Participation deals with an employee and a manager, but here these interactions are between two managers. Changing the interaction to operate between two managers does not alter the sense or validity of our Framework, one is hierarchically different to the other.

We consider the Financial Manager first, as he is the person who will have to change his job and facilitate the work of the Health Centre Manager. In our previous paper we called his initial position with the Health Centre Manager, Sole Participation, as he would be participating with the Health Centre Manager but making the decisions (Purdy and Gago, 2003).

Using our constructions of the legal and institutional material, we anticipate that the Financial Manager will start in the position of having responsibility for particular activities at the Health Centre, the daily activities. Our earlier discussion of the Financial Manager's role indicated he appeared to be in a position of autonomy over the daily activities of a Health Centre. He was taking autonomous decisions.

For us, the word Autonomy means that, a person is able to act and take a decision alone without first referring to or conferring with another, at the time when the decision is taken. The person exercising Autonomy may have referred to and conferred with others before the time when the decision was taken, and so be aware of the views of these others. In using the word Autonomy we consider the person to have taken the decision in the context of the organization, so that this does not mean that the person has personal freedom to act, but organizational freedom to act.

Autonomy did not appear in our earlier Framework. Autonomy is similar to, and might even be argued to be a form of Participation. It might also be argued to be a form of 


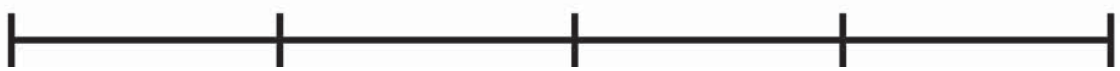

Fig. 5. Anticipations about an influence construct including autonomy.

Consultation. Here we considered Autonomy in the Galician context of regionalisation. Successive Spanish government's messages indicated that the regions would determine their own futures and so we have placed it on our influence construct beyond Participation.

We have chosen to use Autonomy in place of the Sole Participation label that we used in the previous paper, and consider that the Health Centre Manager will develop to work at the Health Centre with similar/same Autonomy to the Financial Manager. These anticipations about an influence construct and autonomy are shown in Fig. 5.

After using the legal and institutional material we now have a different Matrix of Information and Influence. We have amended the Influence construct to deal with the concept of Autonomy but at this stage Information has not still been amended. The Anticipated Interim Matrix is shown in Fig. 6.

\subsection{Influence-Financial Manager}

Over a period of time, it is anticipated that the Financial Manager will move from Autonomy using Local Health Centre Information, through Participation and then subsequently have less influence upon the Health Centre's daily activities as the Health Centre Manager does his job.

It is anticipated that the effect of these changes will alter the Framework of Issues on the Personal Information Influence Matrix of the Financial Manager. The Framework of Issues and the movement on the Financial Manager's Matrix will be as follows:

1. Starts in the Local Information-Autonomy box.

2. After a period of time will interact with the Health Centre Manager and will be located in the Local Information-Participation box.

3. After a short period of time will interact with the Health Centre Manager and so will then be located in the Local Information-Consultation box.

\begin{tabular}{|l|l|l|l|l|l|}
\hline \multirow{2}{*}{ Information } & \multicolumn{5}{|c|}{ Influence } \\
\cline { 2 - 6 } & No influence & Communication & Consultation & Participation & Autonomy \\
\hline Distant Information & & & & & \\
\hline Medium Information & & & & & \\
\hline Local Information & & & & & \\
\hline No information & & & & & \\
\hline
\end{tabular}

Fig. 6. Anticipated Interim Matrix Incorporating Autonomy. 


\begin{tabular}{|l|l|l|l|l|l|}
\hline \multirow{2}{*}{ Information } & \multicolumn{5}{|c|}{ Influence } \\
\cline { 2 - 6 } & No influence & Communication & Consultation & Participation & Autonomy \\
\hline $\begin{array}{l}\text { Distant } \\
\text { Information }\end{array}$ & & & & & \\
\hline $\begin{array}{l}\text { Medium } \\
\text { Information }\end{array}$ & & & & & \\
\hline Local Information & & 4 & 3 & 2 & 1 \\
\hline No information & & & & & \\
\hline
\end{tabular}

Fig. 7. Anticipated movements of the Financial Manager in the Autonomy Matrix in relation to the Health Centre Manager.

4. After a further period of interaction will be located in the Local InformationCommunication box.

5. After a further period of interaction will be located in the Local Different InformationCommunication box.

Currently, we do not know how this local different information is to be regarded.

The anticipated movements of these changes in items 1-4 are shown in Fig. 7.

When the Health Centre Manager achieves autonomy there would be a changed relationship between the managers and the Health Centre Manager reporting on Local Different Information to the Financial Manager. The changed relationship indicates a different Information-Influence Matrix for the Financial Manager with the Health Centre Manager. The Financial Manager would receive the local different information, item 5, from the Health Centre Manager, and this is demonstrated in Fig. 8.

\subsection{Influence-Health Centre Manager}

The Health Centre Manager's job is to gain Autonomy to be able to run the daily activities of the Health Centre. The extent to which this Autonomy occurs will relate to the Financial

\begin{tabular}{|l|l|l|l|l|l|}
\hline \multirow{2}{*}{ Information } & \multicolumn{5}{|c|}{ Influence } \\
\cline { 2 - 6 } & No influence & Communication & Consultation & Participation & Autonomy \\
\hline $\begin{array}{l}\text { Distant } \\
\text { Information }\end{array}$ & & & & & \\
\hline $\begin{array}{l}\text { Medium } \\
\text { Information }\end{array}$ & & & & & \\
\hline Local Information & & & & & \\
\hline $\begin{array}{l}\text { Local Different } \\
\text { Information }\end{array}$ & & 5 & & & \\
\hline No information & & & & & \\
\hline
\end{tabular}

Fig. 8. Anticipated position of the Financial Manager after Health Centre Manager achieves autonomy. 
Manager and his requirements. It is anticipated that the Health Centre Manager will start without knowledge, information and influence but will acquire these and have Autonomy to run the Health Centre's daily activities. It is also anticipated that the Health Centre Manager will obtain the necessary requirements from the Financial Manager or other forms of training.

Again, it is not possible to specify precisely how these matters will occur, but the Health Centre Manager will acquire various parts of Local Information and combine these with different forms of influence, as agreed with the Financial Manager, until a point of Autonomy is reached. When the Health Centre Manager is involved with running the Health Centre, it seems likely that the Health Centre Manager will then become a source of information for the Financial Manager about the Health Centre. Of course, this might occur at any stage, for as soon as a different person becomes involved with the Health Centre the Financial Manager's perceptions about the Health Centre could change through the views of others. We do not have clear anticipations to create a framework for the types of information that will be created from the resulting situation.

In summary, we anticipate that the effect of these changes will alter the Framework of Issues on the Personal Information Influence Matrix of the Health Centre Manager. The Framework of Issues and the movement on the Health Centre Manager's Matrix will be as follows:

1. Starts in the No Information-No Influence box.

2. After a short period of time will interact with the Financial Manager and so will then be located in the Local Information-Communication box.

3. After a further period of interaction will be located in the Local Information-Consultation box.

4. After a further period of interaction will be located in the Local Information-Participation box.

5. After a period of time will be located in the Local Information-Autonomy box.

The anticipated movements of these changes, for the Health Centre Manager on the Autonomy Matrix, are shown in Fig. 9.

\begin{tabular}{|l|l|l|l|l|l|}
\hline \multirow{2}{*}{ Information } & \multicolumn{5}{|c|}{ Influence } \\
\cline { 2 - 6 } & No influence & Communication & Consultation & Participation & Autonomy \\
\hline $\begin{array}{l}\text { Distant } \\
\text { Information }\end{array}$ & & & & & \\
\hline $\begin{array}{l}\text { Medium } \\
\text { Information }\end{array}$ & & & & & \\
\hline Local Information & & 2 & 3 & 4 & 5 \\
\hline No information & 1 & & & & \\
\hline
\end{tabular}

Fig. 9. Anticipated movements of the Health Centre Manager on the Autonomy Matrix. 


\subsection{Information}

From the legal and institutional material, we anticipated that the Financial Manager takes decisions about daily activities after considering "all information". Here "all information" is not clarified or defined as we do not know, and cannot anticipate, what types of information will be available in relation to the Health Centre.

Analysis of the Galician legislation has indicated a number of areas where matters could affect the context of working for the Financial Manager and a Health Centre Manager, and hence affect the research Framework. These matters include the involvement of the community in the determination of the activities of the Centre. The changes are expected to occur within the setting of a Health Centre, along with concerns about how this can be achieved without time and money. The changes in the remuneration of some professionals, the challenges of the notion of people working with retos and how information can be devised to examine the outcomes of a retos for an individual.

We have no idea what types of retos will be used with the Financial Manager and the Health Centre Manager. However, the legislation indicates that objectives will be set and reported upon, therefore, we can anticipate that some of the notions about the retos will be in the form of information. If this is the situation, then this information can be used with an appropriate Information-Influence Matrix.

Our Initial Galician Framework Matrix (Purdy and Gago, 2003) uses the notion of information which is used at various distances of decisions from the person who is being asked for a view. It is anticipated that information, concerning daily Health Centre activities, will be known by the Financial Manager. Further, this information would be regarded as at the level of the Health Centre and in our terminology, Local Information. Currently, for the purposes of the Information-Influence Matrix, these types of information cannot be anticipated by us. This means that the Anticipated Interim Matrix Incorporating Autonomy, Fig. 6, is our final position for individuals.

\section{Organizational and institutional level of analysis}

\subsection{Introduction}

This far, the paper has been concerned with analysing accounting information and influence at the individual level, since this is the subject of one of our interests, approaches and methodologies. It has made more fine and accurate our anticipations about an individual Financial Manager interacting with a Health Centre Manager (Purdy and Gago, 2003). The amendments to our previous Frameworks followed from our consideration and interpretation of the Galician legal pronouncements about the proposed changes.

Although our anticipations have been made more specific, as the sections commenting on the Galician context indicated, these legalities have been unclear in a number of areas. This means that, the overall outcomes will depend upon the overall Galician and/or national policies that are pursued whilst the managers take part in the proposed changes.

These overall policies are at an institutional/organizational level and clearly will affect the individuals in their work. We anticipated that some of the individuals involved 
could encounter difficulties such as the continuation of service levels whilst implementing changes, the financing of these levels and management changes, including any retos.

Our previous literature has emphasized the individuals involved and that managers will have their own individual approaches to handling accounting data and influence (Purdy and Gago, 2003). At the same time some of this literature has recognized that industrial and organizational relationships will be involved. In fact the conceptualization of the Information-Influence Matrix was based on social construction rather than personal construction (Purdy and Gago, 2003). This section will demonstrate our thinking about matters at this institutional/organizational level, in terms of our approaches. This will allow us to analyse some of the institutional/organizational arrangements from our empirical data with our Frameworks and methods of analysis.

\subsection{Previous literature}

The approach to individuals involved in their organization has been to consider the notions about activities that have been available to them. An early commonly found notion was influence. Using the notion of influence it was possible to label some of the circumstances relating to an employee (Purdy and Gago, 2003).

These levels of influence formed a continuum of different constructs. For example, it was accepted that an employee might perceive their organizational position to be that of $\mathrm{No}$ Influence. That is to say the employee perceived he could not exercise any influence. This was considered the position of least influence for an employee, but there were other labels, Communication, Consultation and Participation (Purdy and Gago, 2003). These have been defined earlier in the paper, along with the lack of a position of total influence, and for brevity are not repeated here.

It was accepted that the precise construct about influence would vary with each individual, since each individual was different in terms of personal construct psychology (Kelly, 1955). This meant that with influence, each individual would have their own personal views at any point on this continuum or construct. Each would have their own views for each label. Personal construct psychology considers there is commonality of construing about an issue (Kelly, 1955) and one place where this is likely to occur is in the context of an organization.

The literature considered the individual in an organization context, because research was being conducted with individuals in organizations. Consequently, amongst other matters, the ethos, the attitude in the organization or part of the organization, towards how influence is exercised in the organization, or a part of the organization, helps to determine how employees are dealt with and what forms of influence they work with. This means that it would be possible to have constructs about how influence is exercised by the organization's ethos, but this would also depend upon the individual managers working with influence (Purdy and Gago, 2003).

The earlier parts of the paper have dealt with managers, but here we can use the same/similar construct of influence to apply to that of the organization and use the same/similar words for this. Of course, with personal construct psychology, it is anticipated that there could be different organizational views about the organization's position, depending upon those involved. 


\begin{tabular}{|l|l|l|l|l|l|}
\hline \multirow{2}{*}{ Information } & \multicolumn{5}{|c|}{ Influence } \\
\cline { 2 - 6 } & No influence & Communication & Consultation & Participation & Autonomy \\
\hline $\begin{array}{l}\text { Distant } \\
\text { Information }\end{array}$ & & & & & \\
\hline $\begin{array}{l}\text { Medium } \\
\text { Information }\end{array}$ & & Organization is \\
here & $\begin{array}{c}\text { Organization } \\
\text { moves through } \\
\text { here }\end{array}$ & $\begin{array}{c}\text { Organization } \\
\text { moves through } \\
\text { here }\end{array}$ & $\begin{array}{c}\text { Organization to } \\
\text { be here }\end{array}$ \\
\hline No information & & & & & \\
\hline
\end{tabular}

Fig. 10. Anticipated change of the Health Centre Organization on the Autonomy Matrix.

Turning to accounting data, a similar set of constructs can exist at the level of an organization or part of an organization, as have been used with individuals. Thus, the continuum of data in any organizational situation could be related to the label of No Information, where the organization does not formally provide data in the situation under consideration. At the same time, it is possible to consider an organization having other constructs about the provision of accounting data. The other labels of accounting data are Local Information, Medium Information and Distant Information. These also have been defined earlier in the paper, along with the lack of a position of total information and are not repeated here.

In a similar manner, the exact content of any of these labels of information provision will depend on the organization and the person describing the situation. An earlier empirical study used the accounts and reports from companies newly floated on the London Stock Exchange. These documents provided evidence of each company's stated use of accounting data with employees in their company. The study was able to demonstrate the differences, in Information and Influence for the employees, amongst those companies with respect to types of accounting data and the different organizational influence forms used.

Here the constructs of Information and Influence are brought together in an Organization Information-Influence Matrix, and is shown in Fig. 10. Fig. 10 shows the anticipated outcomes of the Galician legislation and its written policy of an organization which is in the position of providing Local Information in a Communication position, but intends to move to an Autonomy influence position and Local Information. The Matrix starts with the Health Centre Organization at the Local Information-Communication position and indicates the Health Centre's Organization is anticipated to move right towards the Autonomy position. In doing this it moves through Local Information and Consultation, then Local Information and Participation and finally Local Information and Autonomy. These four stages are the Framework of Organization Issues for the Health Centres.

\section{Summary and conclusions}

The authors have used the original literatures to analyse Galician legislation about proposed changes in healthcare with Galician Health Centres. The paper has amended an earlier 
Framework to make it more specific to individual Galician managers. This has been completed in terms of Developed Frameworks for a Financial Manager and a Health Centre Manager working to produce change in Galician healthcare.

The final section of the paper has moved the level of analysis to the organizational/ institutional. This has used similar/the same notions applied with individuals to apply with the organization changes that have been anticipated. It has produced a Developed Framework of Organization Issues for Galician Health Centres.

Both sets of theoretical Developed Frameworks are sufficient for us to analyse empirical data collected from Galician managers involved in changes to Health Centre healthcare.

We have argued our position of acceptance of the legal anticipations and why at this point we have made the amendments to our Framework in the ways we have to reflect this. This is our current position but we are aware that similar moves towards changes in the provision of more information and more influence to employees elsewhere have not occurred smoothly.

We have shown evidence from the UK, the European Community and the US that indicates proposals for changes have been introduced and accompanied by strong narratives about more information provision to employees and more employee involvement. The processes have been different, some changes did not take place, or had been altered either before, during or after introduction. The general outcomes have been similar in that change was more likely to be more favourable for managers than for non-management employees.

The paper contains our dynamic Framework and is only a part of a very complex area of anticipated events. We have chosen these research approaches and these dynamic Frameworks are our personal constructions. Others are quite free to offer other approaches or indeed construe the relevance of the legal background in a different manner to us and the current Framework.

\section{Acknowledgements}

Susana Gago thanks the Spanish Government for funds from SEJ2004-08176-C02-02. An earlier version of this paper was given at the Sixth International Management Control Systems Conference, Management Control Association, Edinburgh Business School, July 2004. The authors thank colleagues for the support and comments received as well as Dominique Bessire, Université d'Orléans, for helpful comments on an earlier draft. We would also like to thank the reviewers for their helpful comments, along with Tony Tinker. A stronger paper has come from this. This is our representation of everyday Galician activities which we have interpreted in our way. Our strongest thanks go to the Galician Financial Manager who helped us with references, access and then read an earlier draft of this paper. His supportive comments about our interpretation of his work area have enabled us to make progress.

\section{References}

Arnold PJ. From the union hall: a labor critique of the new manufacturing and accounting regimes. Critical Perspectives on Accounting 1999;10:399-423. 
Batstone E, Ferner A, Terry M. Unions on the board: an experiment in industrial democracy. Basil Blackwell; 1983.

Brannen P, Batstone E, Fatchett D, White P. The worker directors. Hutchinson; 1976.

Centre for Decision-Making Studies. Report to the Leverhulme Trust on company information to employees project. London: Tavistock Institute of Human Relations; 1979.

Constitución Española. Boletín Oficial del Estado, de 29 de Diciembre de 1978.

Decreto 161/1996, de 25 de Abril, por el que se Modifican Determinados Preceptos del Decreto 200/1993, de 29 de Julio, de Ordenación de la Atención Primaria en la Comunidad Autónoma de Galicia, Diario Oficial de Galicia, 14 de Mayo de 1996.

Decreto 200/1993, de 29 de Julio, Ordenación de la Atención Primaria, 31 August, 167, Aranzadi, 524-28.

Decreto 226/1996, de 23 de Abril, por el que se regula el Régimen Retributivo del Personal de las Unidades y Servicios de Atención Primaria, Diario Oficial de Galicia, 12 de Septiembre de 1996.

Decreto 252/1994, de 29 de Julio, Creación y Estructura Directiva de las Gerencias de Atención Primaria, 9 August, 249, Aranzadi, 583-85.

Decreto 352/ 1998, de 11 de Diciembre, Revisión del Mapa Sanitario de Galicia, 11 December, Aranzadi, n. 398, p. 1173.

Department of Trade. The conduct of company directors. HMSO; 1977a.

Department of Trade. Report of the committee of inquiry on industrial democracy. HMSO; 1977b.

Dewhirst HD. Influence of perceived information-sharing norms on communication channel utilization. The Academy of Management Journal 1971;14(3):305-15.

European Communities Commission. Employee participation and company structure. Bulletin of European Communities 1975 [supplement S/75, London].

European Communities Commission. Proposal for Council Directive on procedures for informing and consulting employees of undertakings with complex structures in particular transnational undertakings. Official Journal of the European Communities 1980 [No. C297/3-8, London].

European Communities Commission. Community Charter of Fundamental Social Rights, Commission Working Documents, 1989 [No. 248].

European Communities Commission. European works council directive. Official Journal of the European Communities 1994 [No. L254].

European Communities Commission. Directive 2002/14EC of European parliament and council of 11 March 2002. Establishing a general framework for informing and consulting employees in the European community; 2002.

European Economic Community. Treaty of Rome (1957). Treaties establishing the European communities, abridged ed.; 1987.

Goodlad, JB. Budgetary control: non-managerial employee involvement. Institute of Cost and Management Accountants. London: Liverpool Polytechnic; 1984.

Kelly GA. The psychology of personal constructs. New York: W.W. Norton; 1955.

Ley 1/1989, de 2 de Enero, de creación del Servicio Gallego de Salud. Boletín Oficial del Estado, de 13 de Febrero de 1989.

Ley 14/1986, de 25 de Abril, General de Sanidad. Boletín Oficial del Estado, de 29 de Abril de 1986.

Ley Orgánica 1/1981 de 6 de Abril de Estatuto de Autonomía para Galicia. Boletín Oficial del Estado, de 28 de Abril de 1981.

Ley Orgánica 11/1985 de 2 de Agosto de Libertad Sindical. Boletín Oficial del Estado, de 8 de Agosto de 1985.

Marsh A, Hussey R. Survey of employee reports. Company secretary's review. London: Tolley; 1979.

Orden 11 Mayo 1995. Desarrolla la Estructura Directiva de las Gerencias de Atención Primaria de Galicia, 25 May, 170, Aranzadi, 423-24.

Parker RJ, Kyj L. Vertical information sharing in the budgeting process. Accounting, Organizations and Society 2006;31(1):27-45

Purdy DE. An examination of the rationales for providing financial and management information to employees in the context of the UK: towards a general rationale of the process from a management perspective. Discussion Papers in Accounting and Finance (No. 11). University of Reading; 1988.

Purdy DE. Accounting, controls, change and the perceptions of managers: a longitudinal study of ward units in a teaching hospital. Financial Accountability and Management 1993;9(1):45-66.

Purdy DE, Gago S. Public sector managers handling accounting data: a UK framework validated in Spain. Financial Accountability and Management 2002;18(3):233-60. 
Purdy DE, Gago S. Towards a framework to study influence and accounting use. Critical Perspectives on Accounting 2003;14:663-78.

Real Decreto Ley 3/1987 de 11 de Septiembre, sobre Retribuciones del Personal Estatutario del Instituto Nacional de la Salud. Boletín Oficial del Estado, de 12 de Septiembre de 1987.

Reeves KT. Information disclosure in employee reports. Employee Relations 1980;2(3).

Scott TW, Tiessen P. Performance measurement and managerial teams. Accounting, Organizations and Society 1999;24:263-85.

Spekman RE. Influence and information: an exploratory investigation of the boundary role person's basis of power. The Academy of Management Journal 1979;22(1):104-17.

The Prime Minister. Industrial democracy. London: HMSO; 1978 [Cmnd. 7231].

Wall TD, Lischeron JA. Worker participation: a critique of the literature and some fresh evidence. New York: McGraw-Hill; 1977. 